\title{
Utilisation of Community Audio Towers in Health Education for Prevention of Cervical Cancer by Health Workers in Kyotera District, Uganda: A Cross-Sectional Study
}

\author{
Richard Kabanda' \\ Everd Bikaitwoha Maniple ${ }^{2}$ \\ Joseph Baruch Baluku (D) ${ }^{3}$ \\ Arthur Kiconco iD ' \\ 'Faculty of Health Sciences, Uganda \\ Martyrs University, Nkozi, Uganda; \\ ${ }^{2}$ Department of Public Health, Kabale \\ University, Kabale, Uganda; ${ }^{3}$ Division of \\ Pulmonology, Kiruddu National Referral \\ Hospital, Kampala, Uganda
}

Purpose: Community audio towers (CATs) are a communication resource that can be utilized by public health practitioners to enhance health communication in rural and periurban settings. However, information on availability of this channel of communication for use in health education and promotion remains scanty. We determined the availability of CATs for use in cervical cancer health education among health workers for prevention of cervical cancer in Kyotera District, Uganda.

Methods: Using a cross-sectional study design, health workers were randomly selected from health facilities in Kyotera District. Eligible participants were health workers who had worked in the district for at least one year. A pre-tested study questionnaire was selfadministered. Descriptive statistics were used to determine availability and use of CATs, while factors associated with the use of CATs were determined by logistic regression analysis.

Results: Between March and April 2020, 160 health workers were enrolled, and of these, $102(63.8 \%)$ were females and $69(43.1 \%)$ were nurses. Most of them, ie, $143(89.4 \%)$ reported that CATs were within walkable distance from their workplaces; $140(87.5 \%)$ indicated that CATs are conveniently located, and $129(80.6 \%)$ reported that it was easy to secure airtime to sensitise communities on health issues. Only $26(16.3 \%)$ had ever used CATs for cervical cancer health education. Health workers at facilities without a plan that includes CATs as a channel of health communication were less likely to utilise CATs (OR = $0.04,95 \%$ CI $(0.0043-0.37), p=0.005)$ while those who had ever managed a patient with cervical cancer $(\mathrm{OR}=16.48,95 \% \mathrm{CI}(3.4-79.7), \mathrm{p}<0.001)$ were more likely to utilise CATs. Conclusion: Although CATs were deemed readily available, there was low utilisation for cervical cancer education and promotion of preventive services by health workers. Health facilities need to strategically include CATs in their plans to increase utilisation.

Keywords: cervical cancer, community audio towers, CATs, health promotion, health communication, health education

\section{Background}

Cervical cancer is a major public health problem that accounted for 311,000 deaths in 2018, of which $88 \%$ were in low resource settings. ${ }^{1}$ The concurrent HIV epidemic is fuelling the incidence of cervical cancer cases and deaths in East and Southern Africa where respectively $64 \%$ and $27 \%$ of women with cervical cancer are living with HIV. ${ }^{2}$ Cervical cancer screening as opposed to vaccination against
Correspondence: Richard Kabanda Martyrs University, P.O Box 5498, Nkozi, Uganda

Tel +256773961965

Email krdent@yahoo.com;

rkabanda@umu.ac.ug 
Human Papilloma Virus (HPV), is the most frequently used prevention strategy in sub-Saharan Africa (SSA). ${ }^{3}$ However, cervical cancer screening coverage is at most $54 \%$ with most studies reporting less than $10 \%$ coverage of screening in SSA. ${ }^{4}$ In Uganda, the cervical cancer screening coverage is low, at $4-35 \%$, across different settings. ${ }^{5-9}$ This is partly due to low knowledge levels on cervical cancer and its prevention. ${ }^{7,9}$ Targeted communitybased cervical cancer health education interventions have been found to increase the uptake of cervical cancer screening by increasing awareness and modifying behaviour among women. ${ }^{10,11}$ Effective and impactful community interventions heavily rely on use of locally available health promotion resources like community audio towers to engage, educate and mobilise communities to seek public health preventive services.

Community Audio Towers (CATs) are a communitybased channel of communication comprised of powerful fixed speakers hoisted on bamboo or steel poles, and can send information in a 5 kilometre radius. ${ }^{12}$ In some communities, CATs are considered area-local FM stations because they disseminate contextually relevant information to communities and are, therefore, ideal for rural settings where access to other media is hampered by cost, literacy levels and a lack of understanding of the local context. ${ }^{12}$ Despite CATs being ideal as a channel where health issues can be communicated in rural communities, evidence about their availability and use in Uganda and across the globe remains scanty.

Therefore, this study focused on determining the availability and utilisation of CATs in health education for prevention of cervical cancer among health workers in Kyotera District, Uganda.

\section{Study Methods Study Setting}

The study was carried out in Kyotera, a rural district located in southern central Uganda between March and April 2020. Kyotera District was part of Rakai district where the first case of HIV/AIDs in Uganda was discovered, located at the border with Tanzania. The district is known for the high HIV prevalence, currently standing at $8.0 \%$ (UPHIA, 2016). There is a known link between HIV/ AIDS and cancers, including cancer of the cervix, which shares similar risk factors. Kyotera is largely a physical community given the fact that it is a rural area that mainly depends on local communication resources to receive information on social issues. Further, the characteristics of individuals enable them to come together for a common goal through use of available resources to address shared challenges, which in this case is prevention of cervical cancer.

\section{Study Population}

This was a cross-sectional study among health workers in Kyotera, a rural district in central Uganda. The study was carried out in selected level three and four (Health Centre IIIs and IV) health facilities and a general hospital in Kyotera District. Eligible participants were health workers employed across these facilities who had worked for at least a year. Working with health facility in-charges, health workers were randomly selected from duty rotas to participate in this study.

\section{Data Collection Tools and Procedures}

After providing informed consent, data were collected using self-administered questionnaires. The questionnaire sought for demographic characteristics of the participants, convenience of accessing CATs and history of CATs utilisation in health promotion. The questionnaire was pretested in Lwengo district, a nearby district to Kyotera.

\section{Sample Size Calculation}

Using the Kish-Leslie formula ${ }^{13}$ and assuming that $50 \%$ of the health workers utilised CATs for cervical cancer health promotion, we estimated that 385 participants would be adequate to determine utilisation of the CATs, considering a 95\% confidence interval. However, the number of health workers in Kyotera District was 271 in 2019 according to the Kyotera District local government health department records. Therefore, using sample size adjustment formula ${ }^{14}$ for a finite population, the sample size was adjusted to 176 participants considering a 10\% nonresponse rate.

\section{Statistical Analysis}

Data were analysed using Stata 14. Data were summarised as frequencies and proportions. At bivariable analysis, associations between utilisation of CATs and each of the independent variables was assessed by ordinary logistic regression to generate crude odds ratios (CORs), their 95\% confidence intervals and p-values. Multi-variable logistic regression analysis was applied to all variables that were significantly associated with CAT utilisation at bivariable analysis. All statistical tests were two-sided; 
95\% confidence intervals were used and variables with p-value $\leq 0.05$ were considered statistically significant.

\section{Ethical Approval and Consent to Participate}

The study was approved by the Institutional Review Board (IRB) of Mildmay Uganda (\#REC 0801-2020) and the Uganda National Council of Science and Technology (UNCST) (SS 5233). Administrative clearance was sought from the Ministry of Health and Kyotera District Local Government. Participants provided written informed consent before data collection was undertaken. All study procedures were in accordance with the Declaration of Helsinki.

\section{Results}

Between March and April 2020, we enrolled 176 health workers. However, 16 did not complete the study questionnaire (a response rate of $91 \%$ ).

\section{Characteristics of Study Participants}

Among the 160 health workers, 102 (63.8\%) were female and majority $(63.1 \%)$ had been employees in the district for 1-6 years. The majority were nurses $(69,43.1 \%)$, laboratory technicians $(32,20.0 \%)$ and midwives $(30$, $18.8 \%$ ). Other characteristics of the study participants are shown in Table 1.

\section{Availability of CATs for Cervical Cancer Health Communication}

Most of the participants, ie 143 (89.4\%), reported that the nearest CAT is within a walkable $(5 \mathrm{kms})$ distance from their workstation. Additionally, 129 (80.6\%) reported that it was easy to secure airtime on CATs for purposes of sensitizing the public on health issues. Furthermore, 114 $(71.3 \%)$ and $115(71.9 \%)$ of the respondents reported that operators of CATs easily accept pre-recorded and printed materials with cervical cancer prevention, respectively. Lastly, 140 (87.5\%) health workers reported that the environment where CATs are located is convenient to health workers for public engagements on prevention of diseases.

\section{Utilisation of CATs for Cervical Cancer Health Promotion Communication}

Among the health workers, 149 (93.1\%) reported that they listen to CATs in their area and 151 (94.4\%) opined that CATs can be used to educate communities' health issues.
However, only 50 (31.3\%) had ever utilised CATs for health promotion, among whom 26 (52\%) had utilised CATs for cervical cancer prevention promotion. Therefore, the overall level of CATs utilisation for cervical cancer prevention communication was $16.3 \%(26 / 160)$. As shown in Figure 1, among those who utilised CATs for health promotion, $29(58.0 \%)$ had utilised them only once in the preceding year.

\section{Factors Associated with Utilisation of CATs for Cervical Cancer Health Promotion}

As shown in Table 2, at multivariate analysis, health workers at facilities without a plan that includes CATs as a channel of health communication ( $\mathrm{OR}=0.04,95 \% \mathrm{CI}$ (0.0043-0.37), $\mathrm{p}=0.005)$ were less likely to utilise CATs, while health workers who had ever participated in the management of a patient with cervical cancer (OR = $16.48,95 \%$ CI $(3.4-79.7), \mathrm{p}<0.001)$ were more likely to use CATs.

\section{Discussion}

This study aimed at determining the availability and utilisation of CATs by health workers in health communication for prevention of cervical cancer in Kyotera District, Uganda. We found that most health workers felt that CATs were within reach from their workplace, conveniently located, and easy for them to secure airtime to sensitise the public on cervical cancer prevention. Moreover, most health workers reported that CAT operators were willing to accept pre-recorded messages and print materials for use in educating the public. Notwithstanding, very few health workers (16.3\%) had ever used the CATs for cervical cancer prevention health promotion. Even among users, majority reported to have sent pre-recorded messages, print materials or appeared physically to sensitise the public only once a year.

We therefore found a disconnect between availability of CATs and actual use. That is, the utilisation of CATs was low despite their availability. This indicates that this cheap and readily available channel is underutilised. It has been shown that middle-aged women (a high-risk population for cervical cancer) are more likely to encounter cancer prevention messages opportunistically rather than purposely seek out for it. ${ }^{15}$ CATs have the potential to provide such opportunistic messages and may prove to be cost effective in rural settings where access to 
Table I Characteristics of Study Participants

\begin{tabular}{|c|c|c|}
\hline Characteristic & Frequency & $\begin{array}{l}\text { Percentage } \\
(N=160)\end{array}$ \\
\hline \multicolumn{3}{|l|}{ Level of Health Facility } \\
\hline $\mathrm{H} / \mathrm{C}$ IV & 17 & 10.63 \\
\hline H/C III & 71 & 44.38 \\
\hline Hospital & 72 & 45.00 \\
\hline \multicolumn{3}{|l|}{ Marital status } \\
\hline Cohabiting & 4 & 2.50 \\
\hline Widowed or Divorced & 7 & 4.38 \\
\hline Never married & 16 & 10.00 \\
\hline Single & 24 & 15.00 \\
\hline Married & 109 & 68.13 \\
\hline \multicolumn{3}{|l|}{ Family history of cancer $(n=\mid 58)$} \\
\hline Yes & 11 & 6.96 \\
\hline Do not know & 24 & 15.19 \\
\hline No & 123 & 77.85 \\
\hline \multicolumn{3}{|l|}{ Years in service } \\
\hline $1-3$ years & 38 & 23.75 \\
\hline $4-6$ years & 63 & 39.38 \\
\hline $7-9$ years & 30 & 18.75 \\
\hline $10+$ years & 29 & 18.13 \\
\hline \multicolumn{3}{|l|}{ Cadre of health worker } \\
\hline Nurse & 69 & 43.13 \\
\hline Laboratory technician & 32 & 20.0 \\
\hline Midwives & 30 & 18.75 \\
\hline Medical clinical officer & 17 & 10.63 \\
\hline Medical officer & 5 & 3.13 \\
\hline Others* & 7 & 4.38 \\
\hline $\begin{array}{l}\text { Ever participated in } \\
\text { management of cervical cancer }\end{array}$ & 57 & 35.63 \\
\hline $\begin{array}{l}\text { Ever trained in health } \\
\text { communication }\end{array}$ & 67 & 42.88 \\
\hline Fluent in local dialect (Luganda) & 158 & 98.75 \\
\hline $\begin{array}{l}\text { Interested in using CATs for } \\
\text { health promotion }\end{array}$ & 144 & 90.00 \\
\hline $\begin{array}{l}\text { Facility has a plan that includes } \\
\text { CATs as a channel of health } \\
\text { communication }(n=159)\end{array}$ & 52 & 32.70 \\
\hline $\begin{array}{l}\text { Facility has dedicated HW to } \\
\text { liaise with CAT operators }\end{array}$ & 49 & 30.63 \\
\hline $\begin{array}{l}\text { Facility has print ICE materials } \\
\text { on cervical cancer }\end{array}$ & 101 & 63.13 \\
\hline
\end{tabular}

Notes: *Includes health educators (4), counsellor (2) and community linkage facilitator (I).

Abbreviations: CAT, community audio towers; ICE, information, communication and education; $\mathrm{H} / \mathrm{C}$, health center; $\mathrm{HW}$, health worker. mainstream media is limited by cost among women with low socio-economic status. Indeed, low social economic status, low level of education and residence in remote and rural settings are reported to be associated with lower odds of being screened for cervical cancer in Uganda due to low knowledge levels regarding cervical cancer. ${ }^{16,17}$ Therefore, CATs have an important role in cervical cancer health communication in rural settings, but they are underutilised. Interestingly, over $90 \%$ of health workers were willing to use CATs and had a positive attitude towards their use. It is therefore unlikely that the low utilisation of CATs observed in our study is due to poor health worker attitude. It is rather likely that the information gathering techniques and priorities of CAT operators affect utilisation of CATs by health workers. Traditionally, in Uganda, individuals with information to be aired on CATs have to walk to the location of the CAT in-person and operators prioritise security issues, death announcements, and emergencies. ${ }^{12}$ Therefore, the utilisation of CATs by health workers was reported to be opportunistic; occurring when there is a health campaign. To resolve this, health facilities need to structure a mechanism of continuous engagement with CAT operators to foster health communication on cervical cancer as discussed below. The low utilisation of CATs in this study could also partly be influenced by the composition of the study participants. A fifth of the health workers were laboratory personnel who have little involvement in health communication and the diagnostic and treatment pathway of cervical cancer. Nevertheless, laboratory staff personnel constitute over $12 \%$ of the workforce in Uganda $^{18}$ and can be integrated in cervical cancer screening programs. ${ }^{19}$ Therefore, this is a neglected section of the health workforce that can be pivotal in health communication for cervical cancer prevention. We have not encountered studies that have evaluated the utilisation of CATs by health workers. We thus are unable to compare our findings with the available literature. In Thailand, CATs have been reported to be used in health communication, although a full description of how health workers were involved is not available. ${ }^{20}$

We found that health workers who had ever managed or participated in managing a patient with cervical cancer were more likely to utilise CATs than their counterparts. This is indicative of how personal experiences of health workers can shape their attitudes and practices regarding health promotion. Health workers who have managed patients with cervical cancer are likely to be more 


\section{5}

30

25

20

15

10

5

0

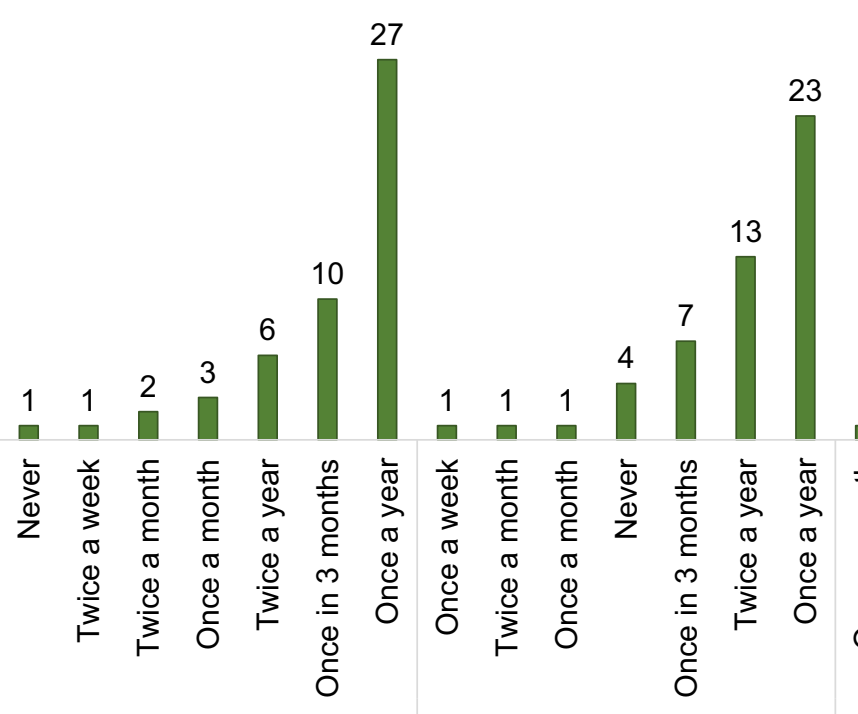

How often do you pre-record How often do you send printed cervical cancer prevention messages for use on CATS material with cervical cancer
messages for use on CATs?

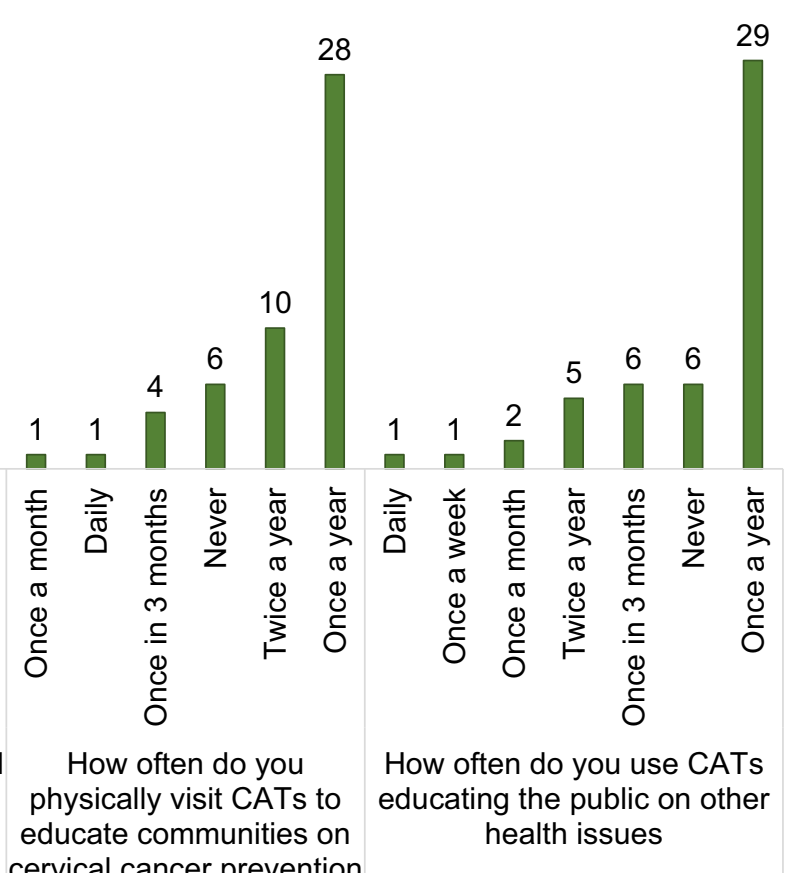

Figure I Frequency of Use of CATs in health communication for cervical cancer prevention.

knowledgeable than their counterparts and this could explain why they were more likely to utilise CATs. Although health communication skills among health workers - which could also influence participation in health communication (and thus utilisation of CATs) - were not assessed, it is apparent from the bivariate analysis that any training in health communication was associated with utilisation of CATs. This suggests that improving health workers' health communication skills could improve their utilisation of CATs. Training of health workers in health communication has potential to improve health worker participation in health communication, and thus utilisation of CATs. $^{21}$

We also found that health workers at health facilities whose work-plan did not include CATs as a channel of health communication were less likely to utilise CATs for cervical cancer health promotion. Our finding highlights the importance of health facility strategic plans in influencing health workers' behaviour in utilisation of health promotion media. Therefore, inclusion of CATs in the health communication strategy of health facilities will improve their utilisation in cervical cancer health promotion. Moreover, having a health worker dedicated to liaison with CAT operators was associated with increased utilisation of CATs at bivariable analysis. Consistent with our findings, one systematic review found that having hospital managers to strategically promote health communication and a culture of health and education promotes nurses' involvement in health communication. ${ }^{22}$ However, in Uganda, the health worker to population ratio is 1 per 1000 persons and health facilities in rural settings are understaffed. $^{23,24}$ Therefore, having a dedicated health worker to liaison with CAT operators may not be feasible in many facilities with large patient volumes. Using community health workers to play this role may be a feasible alternative and their role and impact in health communication for prevention has been demonstrated in rural Uganda. ${ }^{25}$ Additionally, a global systematic review found that community health workers play a key role in raising awareness, conducting or assisting in cervical cancer screening and follow up in low-income countries. ${ }^{26}$ Taken together, the association of CAT utilisation with previous health worker experiences and health facility plans agrees with the socioecological model which attempts to describe how individual and institutional factors can influence regular use of CATs by health workers in educating communities on prevention of cervical cancer and other health challenges. ${ }^{27}$

Our study has some limitations. We did not evaluate health worker knowledge on cervical cancer yet the level of knowledge that a health worker possesses can influence their participation in and utilisation of health promotion resources. 
Table 2 Factors Associated with CATs Utilisation Among Health Workers

\begin{tabular}{|c|c|c|c|c|c|c|}
\hline \multirow[t]{2}{*}{ Characteristic } & \multicolumn{2}{|c|}{ Use CATs for CC-HP } & \multirow[t]{2}{*}{ COR $(95 \% \mathrm{Cl})$} & \multirow[t]{2}{*}{ P-value } & \multirow[t]{2}{*}{ AOR (95\% Cl) } & \multirow[t]{2}{*}{ P-value } \\
\hline & Yes & No & & & & \\
\hline \multicolumn{7}{|c|}{ Ever managed or participated in managing a cervical cancer case $(n=160)$} \\
\hline No & 6 & 97 & & & & \\
\hline Yes & 20 & 37 & $8.74(3.2-23.4)$ & $0.000 * *$ & $16.48(3.4-79.7)$ & $0.000 * *$ \\
\hline \multicolumn{7}{|c|}{ Ever had any training in Health Communication $(n=160)$} \\
\hline No & 8 & 84 & Ref & & & \\
\hline Yes & 18 & 49 & $3.86(1.56-9.52)$ & $0.003 * *$ & $0.51(0.10-2.5)$ & 0.406 \\
\hline \multicolumn{7}{|c|}{ Health facility plans include CATs as a channel of health communication $(n=159)$} \\
\hline Agree & 16 & 36 & & & & \\
\hline Disagree & I & 47 & $0.048(0.006-0.378)$ & $0.004 * *$ & $0.04(0.0043-0.37)$ & $0.005^{* *}$ \\
\hline Neutral & 4 & 16 & $0.56(0.16-1.95)$ & 0.365 & $0.64(0.139-2.9)$ & 0.57 \\
\hline I do not know & 5 & 34 & $0.33(0.11-1.00)$ & 0.050 & $0.48(0.12-1.87)$ & 0.29 \\
\hline \multicolumn{7}{|c|}{ The health facility has a designated health worker who liaises with operators of CATs in provision of Health Education $(n=160)$} \\
\hline Agree & 12 & 37 & Ref & & & \\
\hline Disagree & 5 & 48 & $0.32(0.10-0.99)$ & $0.048 * *$ & $0.95(0.24-3.77)$ & 0.94 \\
\hline Neutral & 2 & 10 & $0.616(0.12-3.21)$ & 0.566 & $0.59(0.08-4.33)$ & 0.61 \\
\hline I do not know & 7 & 38 & $0.567(0.20-0.60)$ & 0.285 & $1.32(0.34-5.11)$ & 0.68 \\
\hline Refuse to answer & 0 & 1 & - & - & - & - \\
\hline
\end{tabular}

Note: **Statistically significant result.

Abbreviations: COR, Crude Odds Ratio; AOR, Adjusted Odds Ration; CAT, community audio towers; CC-HP, cervical cancer health promotion.

A low level of knowledge regarding risk factors, eligibility and frequency of screening among health workers in Uganda has been observed at a national referral hospital. ${ }^{28}$ Additionally, we did not control for the availability and utilisation of alternative media channels in cervical cancer health communication. It is therefore unclear if the availability of other media channels influenced the utilisation of CATs. Further, the low utilisation of CATs as a channel for health communication by health workers may not be limited to CATs, but rather reflective of an overall low participation in community health communication. Also, there was a large confidence interval for the association of "ever managed or participated in managing a cervical cancer case" and use of CATs which could be attributed to the small cell values. Lastly, our study consisted of mostly nurses whose primary role is not health promotion through mass media. This could have underestimated CATs utilisation. Nevertheless, we included all the health educators in the district among respondents as well.

\section{Conclusions}

CATs were reportedly readily available and accessible for cervical cancer health promotion by health workers.
However, the utilisation was very low owing to lack of health facility plans that incorporate their utilisation for health promotion purposes. Health facilities need to strategically include CATs in facility plans as a mechanism of promoting prevention of cervical cancer among individuals in rural communities.

\section{Data Sharing Statement}

Datasets used in this manuscript are available from the corresponding author upon reasonable request.

\section{Acknowledgments}

We thank the administration of Kyotera District for the cooperation throughout the data collection process. The support they provided made the study a success.

\section{Disclosure}

The authors declare no conflict of interest.

\section{References}

1. Arbyn M, Weiderpass E, Bruni L, et al. Estimates of incidence and mortality of cervical cancer in 2018: a worldwide analysis. Lancet Glob Health. 2020;8(2):e191-e203. doi:10.1016/S2214-109X(19) 30482-6 
2. Stelzle D, Tanaka LF, Lee KK, et al. Estimates of the global burden of cervical cancer associated with HIV. Lancet Glob Health. 2020;9 (2):e161-9. doi:10.1016/S2214-109X(20)30459-9

3. Johnson LG, Armstrong A, Joyce CM, Teitelman AM, Buttenheim AM. Implementation strategies to improve cervical cancer prevention in sub-Saharan Africa: a systematic review. Implement Sci. 2018;13(1):28. doi:10.1186/s13012-018-0718-9

4. Lott BE, Trejo MJ, Baum C, et al. Interventions to increase uptake of cervical screening in sub-Saharan Africa: a scoping review using the integrated behavioral model. BMC Public Health. 2020;20(1):654. doi:10.1186/s12889-020-08777-4

5. Osingada CP, Ninsiima G, Chalo RN, Muliira JK, Ngabirano T. Determinants of uptake of cervical cancer screening services at a no-cost reproductive health clinic managed by nurse-Midwives. Cancer Nurs. 2015;38(3):177-184. doi:10.1097 NCC.0000000000000156

6. Twinomujuni C, Nuwaha F, Babirye JN. Understanding the low level of cervical cancer screening in Masaka Uganda using the ASE model: a Community-Based Survey. PLoS One. 2015;10(6):e0128498. doi:10.1371/journal.pone.0128498

7. Waiswa A, Nsubuga R, Muwasi M, et al. Knowledge and attitude towards cervical cancer screening among females attending out Patient Department in Health Centre IIIs in Oyam District. Open J Prev Med. 2017;7(4):55-62. doi:10.4236/ojpm.2017.74005

8. Ndejjo R, Mukama T, Musabyimana A, Musoke D. Uptake of cervical cancer screening and associated factors among women in Rural Uganda: a Cross Sectional Study. PLoS One. 2016;11(2):e0149696. doi:10.1371/journal.pone.0149696

9. Ndejjo R, Mukama T, Kiguli J, Musoke D. Knowledge, facilitators and barriers to cervical cancer screening among women in Uganda: a qualitative study. BMJ Open. 2017;7(6):e016282. doi:10.1136/ bmjopen-2017-016282

10. Agide FD, Garmaroudi G, Sadeghi R, et al. A systematic review of the effectiveness of health education interventions to increase cervical cancer screening uptake. Eur J Public Health. 2018;28 (6):1156-1162. doi:10.1093/eurpub/cky197

11. Naz MSG, Kariman N, Ebadi A, Ozgoli G, Ghasemi V, Fakari FR. Educational interventions for cervical cancer screening behavior of women: a Systematic Review. Asian Pac J Cancer Prev. 2018;19 (4):875-884. doi:10.22034/APJCP.2018.19.4.875

12. Semujju B. Introducing community audio towers as an alternative to community radio in Uganda. J Altern Community Media. 2016;1 (1):141-153. doi:10.1386/joacm_00024_1

13. Israel GD. Determining sample size. University of Florida; 1992. Available from: https://www.psycholosphere.com/Determining\% 20sample\%20size\%20by\%20Glen\%20Israel.pdf.

14. Lavrakas PJ. Encyclopedia of Survey Research Methods. Sage Publications; 2008.

15. Kelly B, Hornik R, Romantan A, et al. Cancer information scanning and seeking in the general population. J Health Commun. 2010;15 (7):734-753. doi:10.1080/10810730.2010.514029

Risk Management and Healthcare Policy

\section{Publish your work in this journal}

Risk Management and Healthcare Policy is an international, peerreviewed, open access journal focusing on all aspects of public health, policy, and preventative measures to promote good health and improve morbidity and mortality in the population. The journal welcomes submitted papers covering original research, basic science, clinical \& epidemiological studies, reviews and evaluations,
16. Black E, Hyslop F, Richmond R. Barriers and facilitators to uptake of cervical cancer screening among women in Uganda: a systematic review. BMC Womens Health. 2019;19(1):108. doi:10.1186/s12905019-0809-z

17. Mukama T, Ndejjo R, Musabyimana A, Halage AA, Musoke D. Women's knowledge and attitudes towards cervical cancer prevention: a cross sectional study in Eastern Uganda. BMC Womens Health. 2017;17(1):1-8. doi:10.1186/s12905-017-0365-3

18. Africa Health Workforce Observatory. Human resources for health: country profile, Uganda; 2009. Available from: http://library.health go.ug/publications/human-resources-health/human-resources-healthcountry-profile-uganda.

19. Tambouret R. Screening for cervical cancer in low-resource settings in 2011. Arch Pathol Lab Med. 2013;137(6):782-790. doi:10.5858/ arpa.2011-0695-RA

20. Tabing L. The development of community media in South-East Asia. Promoting Community Media in Africa Paris. UNESCO; 2000:75-96.

21. Goodman C, Davies SL, Dinan S, Tai SS, Iliffe S. Activity promotion for community-dwelling older people: a survey of the contribution of primary care nurses. Br J Community Nurs. 2011;16(1):12-17. doi:10.12968/bjen.2011.16.1.12

22. Kemppainen V, Tossavainen K, Turunen H. Nurses' roles in health promotion practice: an integrative review. Health Promot Int. 2013;28(4):490-501. doi:10.1093/heapro/das034

23. ACHEST, Wemos. Uganda's Human Resources for Health: Paradoxes and Dilemmas; 2019.

24. Kakyo TA, Xiao LD. Challenges faced in rural hospitals: the experiences of nurse managers in Uganda. Int Nurs Rev. 2019;66(1):70-77. doi:10.1111/inr.12459

25. Musoke D, Ssemugabo C, Ndejjo R, Atusingwize E, Mukama T, Gibson L. Strengthening the community health worker programme for health improvement through enhancing training, supervision and motivation in Wakiso district, Uganda. BMC Res Notes. 2019;12 (1):812. doi:10.1186/s13104-019-4851-6

26. O'Donovan J, O'Donovan C, Nagraj S. The role of community health workers in cervical cancer screening in low-income and middle-income countries: a systematic scoping review of the literature. BMJ Glob Health. 2019;4(3):e001452. doi:10.1136/ bmjgh-2019-001452

27. Kilanowski JF. Breadth of the Socio-Ecological Model. J Agromedicine. 2017;22(4):295-297. doi:10.1080/ 1059924X.2017.1358971

28. Mutyaba T, Mmiro FA, Weiderpass E. Knowledge, attitudes and practices on cervical cancer screening among the medical workers of Mulago Hospital, Uganda. BMC Med Educ. 2006;6(1):13. doi:10.1186/1472-6920-6-13 guidelines, expert opinion and commentary, case reports and extended reports. The manuscript management system is completely online and includes a very quick and fair peer-review system, which is all easy to use. Visit http://www.dovepress.com/testimonials.php to read real quotes from published authors.

\section{Dovepress}

